\title{
Dystrophin nonsense mutation induces different levels of exon 29 skipping and leads to variable phenotypes within one BMD family
}

\author{
leke B Ginjaar ${ }^{1}$, Alexander LJ Kneppers ${ }^{1}$, Jan-Douwe M v d Meulen², \\ Louise VB Anderson ${ }^{3}$, Mattie Bremmer-Bout ${ }^{1}$, Judith CT van Deutekom ${ }^{1}$, \\ Jitske Weegenaar ${ }^{1}$, Johan T den Dunnen ${ }^{1}$ and Egbert Bakker ${ }^{1}$
}

${ }^{1}$ Department of Human and Clinical Genetics, Leiden University Medical Center; ${ }^{2}$ Department of N eurology,
Antonius H ospital, Sneek, The N etherlands; ${ }^{3}$ M uscular Dystrophy Research Laboratories, N ewcastle upon Tyne, UK

Within one X-linked muscular dystrophy family, different phenotypes for three males occurred: (1) a severely affected Becker patient with cardiomyopathy, (2) a mildly affected Becker patient, and (3) an apparently healthy male with elevated serum CK levels. In the muscle biopsy specimen of patient 2 one out of four antibodies (NCL-DYS1) showed absence of dystrophin. The protein truncation test detected a truncated dystrophin for both muscle tissue and lymphocytes of this patient next to an additional near normal size fragment in muscle. Genomic sequence analysis revealed a nonsense mutation in exon 29 $(4148 \mathrm{C}>\mathrm{T})$ of the dystrophin gene. Sequence analysis of the mRNA fragment of the larger peptide showed skipping of exon 29, restoring an open reading frame. Consequently, the epitope of the antibody NCL-DYS1 is mapped to exon 29. The variable clinical features of the three relatives from healthy to severely affected therefore seems to be related to the level of skipping of exon 29 . This finding underscores the future potential of gene therapeutic strategies aimed at inducing exon skipping in Duchenne muscular dystrophy, to generate a much milder disease. European Journal of Human Genetics (2000) 8, 793-796

Keywords: BMD; exon skipping; PTT; nonsense mutation; ERS

\section{Introduction}

Duchenne muscular dystrophy (DMD) and the milder phenotype, Becker muscular dystrophy (BMD), are allelic $X$-linked disorders characterised by progressive degenerative myopathy. ${ }^{1}$ DMD and BMD are both due to mutations in the dystrophin gene on Xp21. The severe DMD phenotype is associated with gross rearrangements (about $65 \%$ of cases) ${ }^{2,3}$ and smaller mutations (the remaining $35 \%$ of cases) ${ }^{3-5}$ which cause premature translational termination and consequently, absence of dystrophin from most ( $>98 \%$ ) or all muscle cells. ${ }^{6}$ The milder variant, BMD, shows a variable phen otype from a slightly less severe, DMD-like condition to very mild symptoms in patients who remain ambulant throughout their

Correspondence: HB Ginjaar, PhD, Dept of Human and Clinical Genetics, Leiden University Medical Centre, Wassenaarseweg 72, 2333 AL, Leiden, The Netherlands. Tel: 3171 5276082;

Fax: 31715271601 ; E-mail: H.B.Ginjaar@kgc.azl.nl

Received 2 May 2000; revised 22 June 2000; accepted 22 June 2000 lives. In BMD patients, markedly elevated serum creatine kinase activity is observed (more than five fold). The involvement of heart muscle seems more prominent in BMD patients with more mildly affected skeletal muscles. ${ }^{7}$ BMD is mostly associated with rearrangements in which the translational reading frame is maintained. ${ }^{8}$ In muscle of BMD patients, dystrophin is present at different levels and/or of altered size. ${ }^{6}$

The dystrophin gene is the largest gene $(2400 \mathrm{~kb})^{3}$ known consisting of 79 exons with multiple promoters and alternative splice sites. ${ }^{9}$ Purine-rich sequences or exon recognition sequences $(E R S)^{10}$ have been reported within some exons of this gene that might act as additional cis elements to permit correct exon recognition. ${ }^{11}$ A nonsense mutation in the putative exon 27 ERS has recently been reported to promote skipping of this exon. ${ }^{12}$ Similar findings have been described for other human diseases. ${ }^{13,14}$ In none of the cases were nucleotide changes in the splicing consensus sequences 
found. In this study we show that a nonsense mutation in an ERS-like sequence of exon 29 also induces (partial) skipping leading to grossly variable clinical phenotypes within one BMD family.

\section{Patients, materials and methods Subjects}

The clinical symptoms of the BMD patients in this family are: patient 1, a 58-year-old male, is wheelchair-bound to bridge longer distances and has progressive muscle weakness, kyphoscoliosis and cardiomyopathy. His younger nephew patient 2 aged 23 has only very mild symptoms, whilst the latter's elder brother relative 3 aged 26 had raised serum CK levels only. Both nephews did not show abnormalities of the calves and had normal ECGs. M uscle biopsy specimens of the two nephews were available for dystrophin analysis.

\section{DNA analysis}

DNA was extracted from the patients' wholeblood, according to the method of Miller et al. ${ }^{15}$ Multiplex PCR was performed according to Chamberlain and Beggs ${ }^{9}$ and Southern blotting was after Bakker and den Dunnen. ${ }^{16}$ Eight highly informative intra- and extragenic STR markers ${ }^{16}$ were used for microsatellite genotyping as indicated in Figure1. Approximately $200 \mathrm{ng}$ of the PCR product generating the truncated translation product was used for sequence analysis. Sequencing was performed using the Big Dye Terminator Sequencing kit (Applied Biosystems, Nieuwekerk a/d IJssel, Netherlands) on an ABI PRISM 310.

\section{PTT assay}

RNA was isolated from muscle tissue specimens and whole blood using RNAzol (Campro Scientific, Veerendaal, Netherlands) according to the manufacturer's protocol. RT-PCR and the protein truncation test (PTT) was performed as described by Roest et al. ${ }^{17}$

\section{Immunohistochemistry}

Serial unfixed cryostat sections of muscle specimens of family members 2 and 3 were studied for dystrophin and spectrin expression. The following antibodies were used against spectrin (NCL-SPEC1 from Novocastra Laboratories Ltd, Newcastle upon Tyne, UK) and dystrophin (NCL-DYS1/2/3, Novocastra; $M$ andys $108^{18}$ ). The immunohistochemical stainings were done as described previously. ${ }^{19}$

\section{Results and discussion}

Initial mutation analysis of the oldest BMD patient in this family did not show any deletion or duplication in the dystrophin gene. Haplotype analysis of the dystrophin gene region showed the same $X$ chromosome in all three male relatives (Figure 1 ) suggesting an $X$-linked inheritance pattern. A muscle biopsy taken from patient 2 showed absence of dystrophin using antibody NCL-DYS1 (Figure2A), whereas it

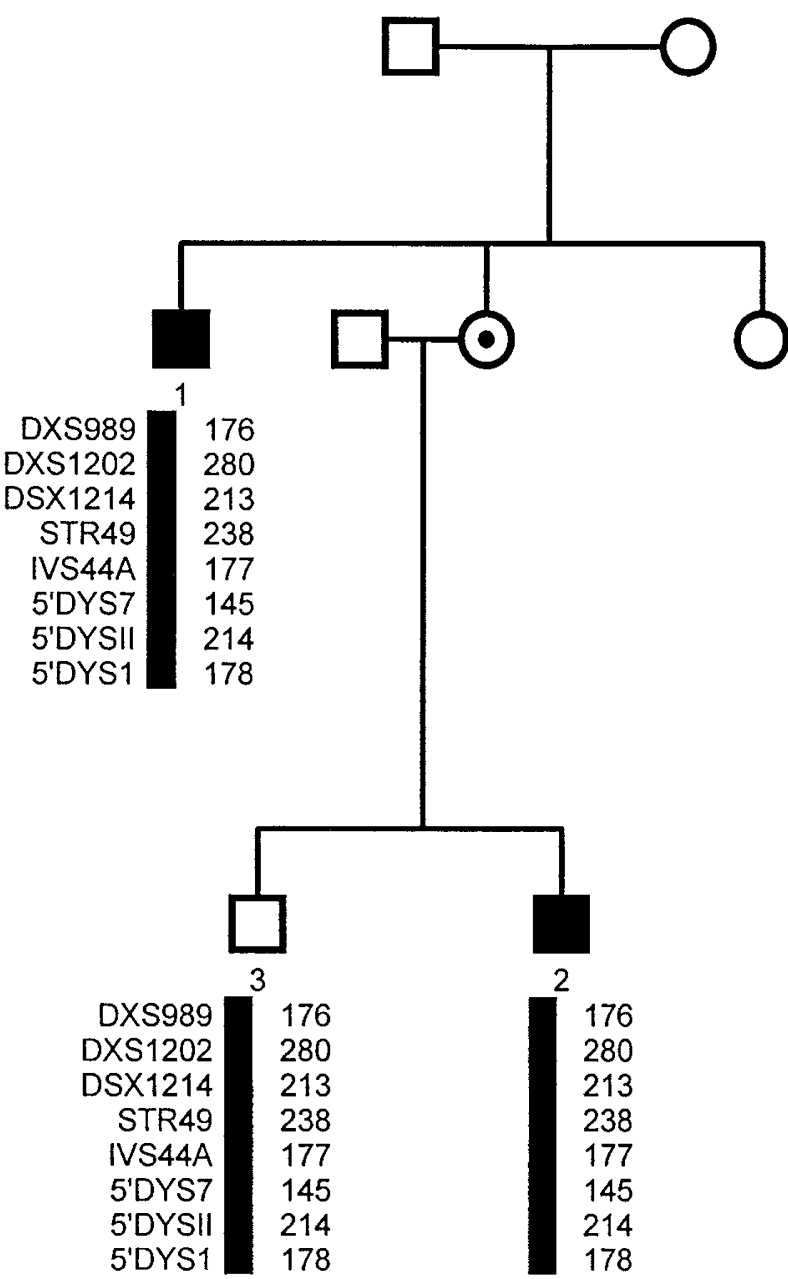

Figure 1 Pedigree of BMD family. For haplotype analysis the extragenic STRs DXS 989, DXS1202 are used; the remaining markers indicated are intragenic.

was present using NCL-DYS3, MANDYS108 (Figure2B) and NCL-DYS2; spectrin was normally expressed (Figure2C). The same results were found for relative3. Muscle tissue of patient 1 was not available for protein analysis. By means of Western blot analysis a reduced amount of dystrophin in relatives 2 and 3 was observed. These results confirmed our immuno-histochemical data suggesting a dystrophinopathy in this family.

Since the immunohistochemical analysis indicated a mutation in the NCL-DYS1 antigenic region of dystrophin, the corresponding part of the gene (exons encoding amino acids 1181-1388) was analysed using RT-PCR (primerset 2E$2 \mathrm{~F}$ ) and the protein truncation test (PTT). A truncated $32 \mathrm{kDa}$ protein fragment was detected using RNA isolated from the lymphocytes of patient 2 (Figure3; lane L). Subsequent genomic sequence analysis revealed a nonsense mutation in exon 29 (4148C >T; Arg1314X) of the dystrophin gene. The 

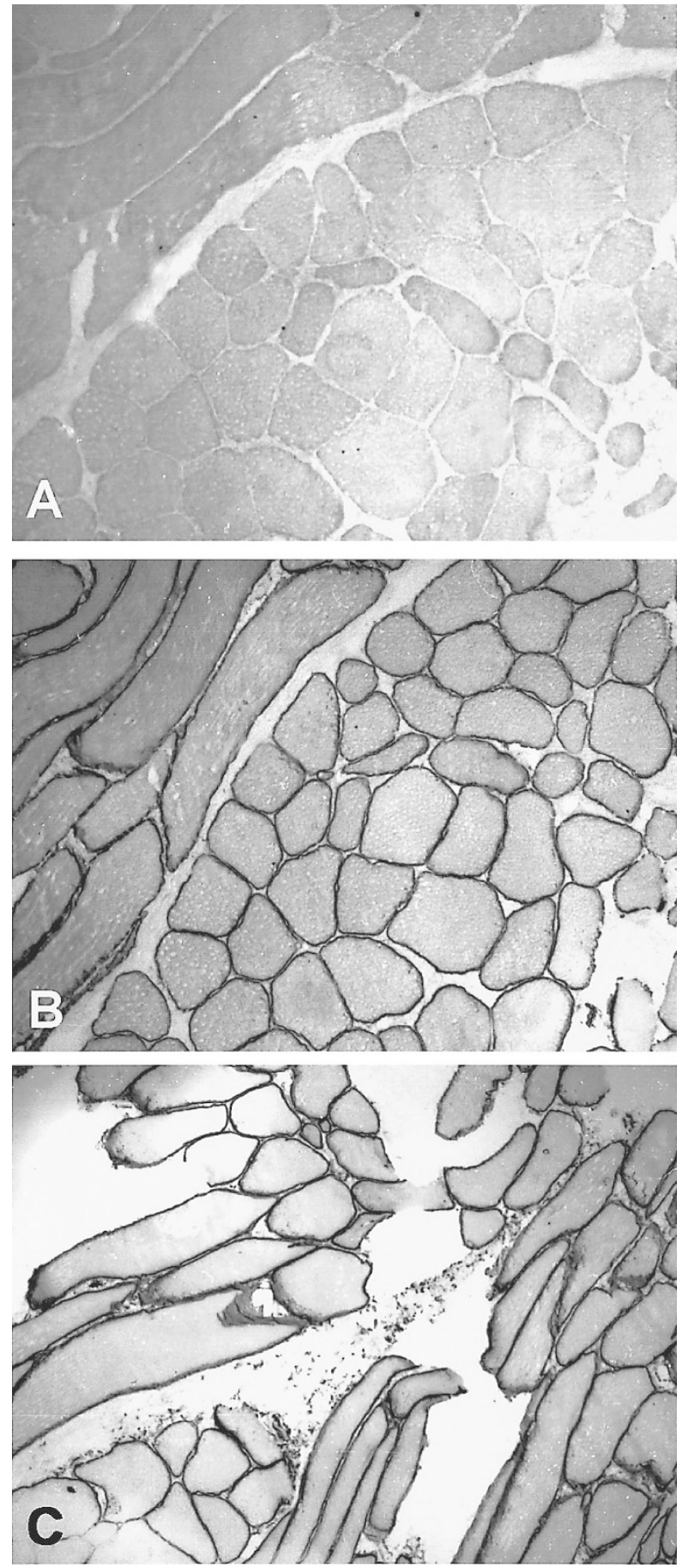

Figure 2 Immunohistochemical labelling of dystrophin and spectrin in skeletal muscle of patient 2. Serial sections were immunostained with A NCL-DYS1 (within amino acids 1181-1388 of dystrophin); B MANDYS108 (within amino acids 1749-2248 of dystrophin) and C NCL-SPEC1 (spectrin).

same nonsense mutation was found in patient 1 and relative3. Remarkably, using RNA isolated from muscle tissue of patient2, a near full-size $42 \mathrm{kDa}$ dystrophin peptide was detected in addition to the truncated $32 \mathrm{kDa}$ dystrophin band observed in lymphocytes (Figure3; lane M). Both PTT products were also found in the muscle tissue of relative 3 (not shown). Apparently, splicing regulation in muscle differs from that in blood.

Sequence analysis of the $42 \mathrm{kDa}$ dystrophin encoding fragment showed the absence of exon 29. The original nonsense mutation is apparently bypassed in a percentage of muscle transcripts by altered splicing, ie skipping of exon 29, which restores the dystrophin open reading frame. Since immunohistochemical analysis of these patients showed absence of dystrophin using monoclonal antibody NCLDYS1, the epitope to which NCL-DYS1 (within amino acids 1181-1388) is directed, has been mapped to exon 29. In this report, we describe a nonsense mutation, expected to cause DMD, in a BMD patient, his mildly affected nephew and his unaffected nephew, the latter with high serum CK levels as the only clinical abnormality. The various clinical features of the three relatives are most likely due to different levels of exon 29 skipping. This apparently leads to a higher level of partly incomplete but functional dystrophin in the mildly affected patient and a proficient level of this protein in his healthy brother.

The consensus sequences splice acceptor and donor sites of exon 29 were unaltered and are weak according to the NetGene2 splice site prediction server. ${ }^{20}$ The mutation $4148 \mathrm{C}>\mathrm{T}$ is predicted to reduce even further the effectiveness of the splice acceptor site of exon 29. We hypothesise that the $\mathrm{C}$ to $\mathrm{T}$ transversion at the 19th nucleotide of exon 29 may interrupt a potential ERS. Previous reports have described ERSs in dystrophin exons19 and 27..1212 Alternatively, the not well understood process of nonsense-

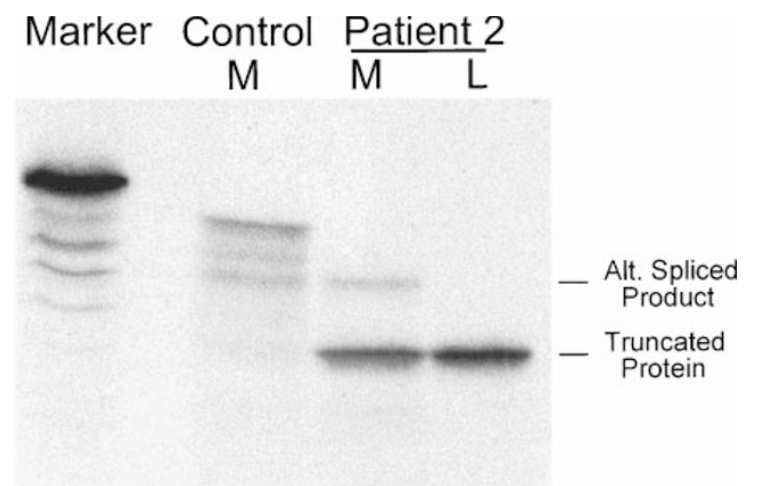

Figure 3 Protein truncation test products from primer set $2 \mathrm{E}-2 \mathrm{~F}$ (exon 23-32) of normal control muscle and muscle tissue and lymphocytes of patient 2 . In control muscle (M) the wild type $52 \mathrm{kDa}$ protein band is shown, in muscle tissue of patient2 (M), the truncated $32 \mathrm{kDa}$ protein band and the alternatively spliced $42 \mathrm{kDa}$ protein product (exon 29 skipped) is found. In the lymphocytes ( $\mathrm{L}$ ) of patient 2 the truncated $32 \mathrm{kDa}$ protein band is seen only. The size marker was luciferase control (Tnt-kit). 
mediated mRNA decay ${ }^{22}$ might be involved, activated by the in-frame stop codon mutation. The same dystrophin nonsense mutation was very recently reported in a family with $X$-linked early onset dilated cardiomyopathy. ${ }^{23}$

Our observations support the development of alternative gene therapy approaches based on modulation of splicing to bypass DMD-causing mutations in the endogenous dystrophin gene. Recent studies show that by using antisense oligonucleotides directed to sites involved in the dystrophin splicing process, the original reading frame can be restored by targeted skipping of specific exons from the pre-mRNA. ${ }^{21,24,25}$ Consequently, despite an internal in-frame deletion, a partially functional dystrophin may be generated similar to those found in milder BMD patients.

\section{References}

1 Emery AEH: Duchenne Muscular Dystrophy. Oxford University Press: Oxford, 1993, pp 115-120.

2 Koenig M, Beggs AH, Moyer $M$ et al: The molecular basis for Duchenne versus Becker muscular dystrophy: correlations of severity with type of deletion. Am J Hum Genet 1989; 45: 498-506.

3 Dunnen JT den, Grootscholten PM, Bakker E et al: Topography of the Duchenne muscular dystrophy (DMD) gene, Fige and CDNA analysis in 194 cases reveals 115 del etions and 13 duplications. Am J Hum Genet 1989; 45: 835-847.

4 Bulman DE, Gangopadhyay SB, Bebchuck KG et al: Point mutation in the human dystrophin gene: Identification through western blot analysis. Genomics 1991; 10: 457-460.

5 Roberts RG, Bobrow M, Bentley DR: Point mutations in the dystrophin gene. Proc Natl Acad Sci 1992; 89: 2331-2335.

6 Hoffman EP, Fisch beck KH, Brown RH et al: Dystrophin characterization in muscle biopsies from Duchenne and BMD patients. N Engl J Med 1988; 318: 1363-1368.

7 De Visser M, de Voogt WG, de la Riviere GV: The heart in Becker muscular dystrophy, fascioscapulohumeral dystrophy, and Bethlem myopathy. Muscle Nerve 1992; 15: 591-596.

8 Monaco AP, Bertelson CJ, Liechti-Gallati S et al: An explanation for the phenotypic differences between patients bearing partial deletions of the DMD locus. Genomics 1988; 2: 90-95.

9 Bakker E, van Ommen GJB: Duchenne and Becker muscular dystrophy (DMD and BMD). In AEH Emery (ed). Neuromuscular Disorders: Clinical and Molecular Genetics, John Wiley \& Sons: Chichester, 1988, pp 59-85.
10 Watakabe A, Tanaka K, Shimura Y: The role of exon sequences in splice site selection. Genes Dev 1993; 7: 407-418.

11 Matsuo M, Masumura H, Nishio $\mathrm{T}$ et al: Exon skipping during splicing of dystrophin mRNA precursor due to an intraexon deletion in the dystrophin gene of Duchenne muscular dystrophy Kobe. J Clin Invest 1991; 87: 2127-2131.

12 Shiga N, Takeshima Y, Sakamoto H et al: Disruption of the splicing enhancer sequence within exon 27 of the dystrophin gene by a nonsense mutation induces partial skipping of the exon and is responsible for Becker muscular dystrophy. J Clin Invest 1997; 100: 2204-2210.

13 Das S, Levinson B, Whieney $C$ et al: Diverse mutations in patients with Menkes disease often lead to exon skipping. Am J Hum Genet 1994; 55: 883-889.

14 Hull J, Shackleton S, Harris A: The stopmutation R553X in the CFTR gene results in exon skipping. Genomics 1994; 19: 362-364.

15 Miller SA, Dykes DD, Polesky HF: A simple salting out procedure for extracting DNA from human nucleated cells. Nucleic Acids Res 1988; 15(3): 1215.

16 den Dunnen JT, Bakker E: http://www.dmd.nl

17 Roest PAM, Roberts RG, Sugino S van Ommen GB, den Dunnen JT: Protein Truncation Test (PTT) for rapid detection of translation terminating mutations. Hum Mol Genet 1993; 2: 1719-1721.

18 Nguyen thi Man, Ellis JM, Ginjaar IB et al: Monoclonal antibody evidence for structural similarities between the central rod regions of actinin and dystrophin. FEBS Lett 1990; 262: 237-240.

19 Ginjaar HB, van der Kooi AJ, Ceelie H et al: Sarcoglycanopathies in Dutch patients with autosomal recessive Limb Girdle muscular dystrophy. J Neurol (in press).

20 Brunak S, Engel bracht J, Knudsen S: Prediction of human mRNA donor and acceptor sites from the DNA sequence. J Mol Biol 1991; 220: 49-65.

21 Pramono ZAD, Takeshima $\mathrm{Y}$, Alimsardjono $\mathrm{H}$ et al: Induction of exon skipping of the dystrophin transcript in lymphoblastoid cells by transfecting an antisense oligodeoxynucleotide complementary to an exon recognition sequence. Biochem Biophys Res Commun 1996; 226: 445-449.

22 Hentze MW, Kulozik AE: A perfect message: RNA surveillance and nonsense-mediated decay. Cell 1999; 96: 307-310.

23 Franz WM, Müller M, Müller OJ et al: Association of nonsense mutation of dystrophin gene with disruption of sarcoglycan complex in X-linked dilated cardiomyopathy. Lancet 2000; 355: 1781-1785.

24 Dunckley MG, Manoharan M, Villiet P, Eperon IC, Dickson G: Modification of splicing in the dystrophin gene in cultured $\mathrm{Mdx}$ muscle cells by antisense oligoribonucleotides. Hum Mol Genet 1998; 7: 1083-1090.

25 Wilton SD, Lloyd F, Carville $K$ et al: Specific removal of the nonsense mutation from the $\mathrm{mdx}$ dystrophin mRNA using antisense oligonucleotides. Neuromusc Disord 1999; 9: 330-338. 